Escuela de Ciencias Sociales y Humanidades, UNED, C.R. URL: http://investiga.uned.ac.cr/revistas/index.php/espiga/index

\title{
La Reforma, un nuevo paradigma de la teología
}

\author{
Martin Hoffmann*
}

Recibido: 02 de marzo, 2016 • Aceptado: 29 de marzo, 2017

\section{RESUMEN}

A 500 años del origen del protestantismo, se plantea la pregunta: ¿Cuál es el significado de la Reforma para hoy? El autor sostiene que la importancia de la Reforma va más allá de una época histórica o de una controversia teológica de su tiempo. Más bien la Reforma es un proceso permanente, un movimiento y un cierto método del quehacer teológico. Remontándose a la teología de la cruz del apóstol Pablo, Martín Lutero, el iniciador de la Reforma, desarrolló un nuevo paradigma de la teología. Es caracterizado por tres aspectos: La cruz como principio epistemológico, la justicia de Dios como contenido esencial del Evangelio, y una ética discursiva de los mandamientos. Este paradigma de la teología posibilita una renovación y una transformación continua de las iglesias y de la teología enfrente de los desafíos contemporáneos como las crisis de la ecología, de la economía, de la justicia social y el aumento de violencia y guerras. La actualidad de la Reforma se demuestra en su nuevo modo de pensar y de actuar, o sea en su potencial crítico a partir del Crucificado y sus perspectivas constructivas para la humanidad y la convivencia a partir de la justicia de Dios.

Palabras clave: Reforma, paradigma, teología de la cruz, justicia liberadora, ética discursiva, convivencia, humanidad.

\section{Formato de citación según APA}

Hoffmann, M. (2017). La Reforma, un nuevo paradigma de la teología. Revista Espiga, 16(33), 19-32. DOI: http://dx.doi.org/10.22458/re.v16i33.1763

\section{Formato de citación según Chicago}

Hoffmann, Martin. «La Reforma, un nuevo paradigma de la teología». Revista Espiga, 33 (2017): 19-32. DOI: http://dx.doi.org/10.22458/re.v16i33.1763

* Luterano, posee estudios de Teología Protestante en Alemania y Escocia. Doctor en Teología, RuhrUniversidad Bochum (Alemania). Desde 2012 hasta 2014 Profesor de la Teología Sistemática en la UBL, Costa Rica. Ahora pastor de la Iglesia Luterana en Baviera y docente visitante en las Iglesias Luteranas de Centro América, a partir de julio 2017 Profesor en la UBL de nuevo. Alemania. martin.dr.hoffmann@gmail.com 


\section{Introducción}

Los 500 años del protestantismo, son más que una fecha histórica y más que la sola descripción del paisaje religioso del mundo. Los 500 años nos hacen recordar el día del 31 de octubre, 1517, cuando el monje Martín Lutero clavó sus 95 tesis contra la práctica de la penitencia por medio de las indulgencias en la puerta de la iglesia del castillo en Wittenberg en Alemania. Aunque esta acción no es tan cierta históricamente, la siguiente publicación de las tesis significa un ataque masivo contra el sistema de la Iglesia católica romana y, por lo tanto, es considerada como el comienzo de la así llamada Reforma.

Igualmente esos 500 años describen el proceso en el cual se originaba una gran variedad de iglesias derivadas de esa Reforma, primero las iglesias luteranas y reformadas, y luego las iglesias anglicanas, menonitas, metodistas, pentecostales y muchas otras. De todos modos, el protestantismo tiene que ver con el origen de la Reforma.

Sin embargo, la importancia de la Reforma puede ser devaluada fácilmente. Dicen que la Reforma es solamente una época histórica, la época en que se expresa una crítica necesaria de algunos problemas de la Iglesia romana de la Edad Media. En este caso, el concilio tridentino (1545-1563) habría cumplido con las pretensiones de purificación y renovación del movimiento. Una variante de esa mirada es la reducción del significado teológico de la Reforma, al manifestar que sea una mera discusión teológico-académica sobre la correcta comprensión del sacramento de la penitencia y de la doctrina de la justificación. En este sentido, no tendría una relevancia actual y estaría muy alejada de la problemática religiosa del presente.

Otra desvalorización consiste en decir que el protestantismo en sí mismo demuestra el escándalo de la división de la iglesia cristiana. Ambas perspectivas disminuyen el valor de la Reforma en lo histórico o en lo teológico. No aciertan la idea central de la Reforma como origen y del protestantismo como consecuencia. Por lo tanto, es necesario aclarar lo que es la Reforma.

\section{El fenómeno de la Reforma}

El término «reformatio» se encuentra solamente en dos pasajes de la Biblia latina, pero son de mucha importancia: en Ro 12:2: «No se amolden al mundo actual, sino sean transformados (reformamini) mediante la renovación de su mente» (Biblia NVI). En Fil 3:21: «Él transformará (reformabit) nuestro cuerpo miserable para que sea como su cuerpo glorioso, mediante el poder con que somete a sí mismo todas las cosas» (Biblia NVI). Ambos versículos describen en conjunto el doble movimiento de la fe como Pablo la expresa. El actuar de Dios con nosotros en Jesucristo y nuestro actuar hacia Jesucristo y lo que deviene de él. Reforma en este sentido es la dialéctica entre la pasividad y la actividad del creyente.

La Reforma confía en lo que es más allá del mundo y al mismo tiempo guía al mundo de una manera nueva. La Reforma se origina en el escuchar y en el esperar de lo que viene. Es diferente de nuestros planes y estrategias de una renovación y optimización de la vida individual, social o eclesial. 
A partir del 1215 el término «Reforma» fue usado en el contexto eclesial. Se convocaron concilios papales «ad reformationem universalis ecclesiae» (para la reforma de la iglesia universal). Primero, la Reforma se refirió a los monasterios y obispados, y luego, a la Iglesia en general. El ímpetu de las pretensiones de la Reforma continuó en Lutero y los otros reformadores. Ellos encontraron en la Biblia la única fuente y el único criterio de la iglesia, la única norma para la doctrina y la vida cristiana.

Este descubrimiento y esta definición impulsaron un proceso de renovación permanente dentro de la iglesia y fuera en su posicionamiento en la sociedad. Esa Reforma continua se debe a una manera nueva de pensar teológicamente.

La teología ya no es la conservación y administración de las doctrinas eclesiales, tampoco es la defensa de las tradiciones o la guarda de las convenciones morales, sino un descubrir de las perspectivas de una vida plena en la Biblia para las situaciones y desafíos actuales. Por eso, se resume que la Reforma generó un nuevo paradigma de la teología. Eso es la causa de su actualidad. La Reforma brinda un modelo para confrontar y tratar los retos de nuestro tiempo. ¿En qué consiste este paradigma?

Si entendemos por un paradigma una manera fundamental de pensar y una visión general del mundo, queda claro que el paradigma contiene dos aspectos: uno en cuanto a la forma (el pensar) y otro, en cuanto al contenido (la visión). Ambos aspectos determinan un cierto pensar de un tiempo, sus preguntas, métodos y el marco general de las respuestas. En este sentido, descubrimos en la Reforma, especialmente en la teología de Martín Lutero, el promotor espiritual de la Reforma, tres aspectos de un nuevo paradigma teológico: una nueva epistemología, un nuevo entendimiento del Evangelio y una nueva concepción de la ética cristiana. ${ }^{1}$

\section{La cruz como principio teológico: Una nueva epistemología}

Lutero presentó su nueva teología por primera vez en La disputación de Heidelberg en 1518. La Orden de los Agustinos Ermenitas, a la que Lutero pertenecía, realizó esa disputa para confrontar las ideas reformadoras de Lutero con sus oponentes de la teología escolástica. Lutero defendió su crítica de las 95 tesis con la exposición de su teología de la cruz bajo el título «Theologica Paradoxa». Con eso puso en relieve el carácter de su teología. Él contrapone explícitamente sus tesis paradójicas de la teología de la cruz, a la teología de la gloria de la Iglesia católica romana.

Este camino se basa en las cosas creadas, en la obra divina, y a partir de ahí deduce la existencia invisible de Dios. La deducción se basa en la capacidad humana de trascenderse a sí mismo y en el anhelo de buscar continuamente una unidad entre todas

1. Nos referimos con esa descripción a Giacomo Cassese, Lutero al Habla. Ed. con Eliseo Pérez Álvarez. (Buenos Aires: Ediciones La Aurora, 2005), IX-XXI. Cassese caracteriza la Reforma por tres aspectos: su nueva epistemología, su crítica de la religión y su nueva opción ética. Es una valiosa descripción, que enfatiza los aspectos formales de la teología reformadora. A mi juicio haría falta añadir los aspectos correspondientes del contenido para completar la imagen de la Teología de la Reforma. Por eso, intentaré en lo siguiente exponer esa parte del contenido un poco más. 
las cosas creadas. Se deduce a través de la razón entre el ser humano y Dios. Las obras morales del ser humano son igualmente obras creadas y sirven como vías de acceso al conocimiento de Dios.

Así Dios pasa a ser el garante de una moral determinada o la explicación de todo el universo, anhelada por la razón humana. En ambos casos, Dios es utilizado e instrumentalizado según los deseos y las intenciones humanas. Unos siglos después el filósofo Anselm Feuerbach criticó esa conclusión de la razón como proyección de deseos humanos.

Lo mismo pasa en el conocimiento de la realidad. La Iglesia misma es parte del sistema político y económico imperante de su tiempo y ejerce poder político y económico, no solo militarmente (Cruzadas, guerras otomanas), sino que además encuentra su legitimación en la religión. La Iglesia sacraliza las estructuras sociales. Dios es definido como el Ser supremo que crea en este mundo un orden jerárquico, el cual es como una escala descendente para evitar el caos social. Este orden va de reyes a príncipes, de nobles a ciudadanos y llega hasta el pueblo y los siervos. En él se refleja por así decirlo el eterno orden divino, que corresponde a su mismo Ser. El orden jerárquico de la Iglesia está estructurado de la misma manera, partiendo del papa, pasando por los obispos y llegando a los sacerdotes.

Todo eso es para Lutero la característica de una teología de la gloria que confía en la capacidad de la razón humana y construye una visión gloriosa de Dios y del mundo. Es la teología escolástica que se apoya en la lógica filosófica de Aristóteles.

Contra ese paradigma Lutero pone sus tesis 19 y 20 de la disputa de Heidelberg: «No se puede con derecho llamar teólogo, a aquel que considera que las cosas invisibles de Dios se comprenden por las creadas. Más merece ser llamado teólogo aquel que entiende las cosas visibles e inferiores de Dios, considerándolas a la luz de la Pasión y de la Cruz». ${ }^{2}$

El conocimiento de Dios comienza según este acceso cuando Dios se da a conocer a sí mismo: en su humanidad, en el rostro que se vuelve hacia nosotros, en Jesucristo. Pero este conocimiento no es claramente visible, sino que está oculto bajo la debilidad, la necedad, el sufrimiento y la cruz, todos fenómenos que generalmente se presentan como opuestos a la divinidad. Dios no se revela directa, sino indirectamente, se podría decir que se da a conocer oculto en lo que le es opuesto. Es por esto que no puede existir un conocimiento directo de Dios. Al conocimiento de Dios no se llega tampoco por la vista, sino por medio de una comprensión y entendimiento que aprehende la presencia de Dios, a pesar de su ocultamiento, en la cruz y en la pasión.

El ser humano vive por naturaleza en un engaño sobre sí mismo y, por lo tanto, también sobre Dios. Esa negación del Dios verdadero solo puede ser revelada mediante la negación de la negación, y esto es precisamente lo que ocurre en la cruz. Dios se revela en el ocultamiento, en su opuesto y es justamente así que el ser humano puede verse a sí mismo y a su situación con otros ojos.

2. La disputación de Heidelberg (1518), en Obras de Martín Lutero, Tomo I. (Buenos Aires: Editorial Paidós/ El Escudo, 1967), 31. 
La cruz significa en este contexto una transformación de valores que parecen naturales. Padecimiento y humillación, cosas que normalmente parecen que separan de Dios y le contradicen, se convierten en señales de la presencia de Dios en el mundo.

Decisivo es que Lutero no solo conoce en la cruz un fracaso de Cristo, sino una victoria. Eso es lo paradójico y, por lo tanto, Lutero nomina su teología de la cruz también teología paradójica. Por la resurrección de Cristo se puede decir que la cruz es el triunfo de Cristo, el triunfo del amor, el triunfo del camino de la no-violencia y de la entrega de su vida.

Lo que según la sabiduría del mundo parece una locura, esto es enfrentar los poderes que esclavizan a los seres humanos, utilizando como armas el sufrimiento y la renuncia a la violencia, resulta más sabio que la locura del mundo. Cruz y resurrección son dos caras de la misma moneda.

Lutero no inventó por sí mismo este principio epistemológico teológico, sino que redescubrió y retomó la herencia de Pablo. La teología de la cruz de Pablo desplegó una nueva fuerza explosiva en la interpretación de Lutero, al concentrarse en la cruz y la resurrección él formuló este nuevo paradigma de la teología. El conocimiento de Dios y de la realidad humana dependen de la auto-revelación de Dios.

Eso cambia la imagen de Dios desde un juez severo y arbitrario, según la razón humana hacia el Dios frágil, sufriente, compasivo y solidario con nosotros, según su revelación en la cruz. Además, esa imagen nueva es símbolo de la esperanza de que Dios niegue el sufrimiento y esté luchando contra el mal según la resurrección. Los conquistadores de América Latina habían eliminado significativamente este aspecto de su teología. A la cruz de Cristo pertenece una ética de la esperanza y de la lucha.

Además, el nuevo paradigma cambia el conocimiento de la realidad humana. Primero, el Cristo crucificado no explica humanidad desde arriba, desde la gloria o desde el poder. Él muestra una humanidad desde abajo, desde la perspectiva de un sufriente, de un torturado y de un abatido. Eso significa que no hay una humanidad o una buena vida sin el respeto de las víctimas y de la responsabilidad para los débiles de una sociedad.

Segundo, el Cristo crucificado no define humanidad desde el centro de nuestros pensamientos, desde nuestros rendimientos, capacidades, posibilidades e intenciones por buenos que sean. Más bien describe la humanidad desde el margen de lo acostumbrado, es decir, desde las heridas y defectos del ser humano y de la sociedad humana. Para la ética cristiana eso significa que encontramos una humanidad verdadera solamente cuando nos atrevemos a pasar las convenciones, tradiciones o normas familiares si es necesario. Pensar desde el margen es un acto de la libertad y apunta a libertad.

\section{El descubrimiento de la justicia liberadora de Dios}

Cassese ve la segunda característica formal de la Reforma en su crítica de la religión. Explica:

Una vez que Lutero divide a toda la teología cristiana en teología de la cruz vs teología de la gloria, se derriten con las máscaras de la religión. Lutero demostró que la gloria era inaccesible 
para la razón humana porque Dios no tenía la intención de mostrar ni revelar su gloria, de ahí, que toda teología falsa es aquella que promete aquello que Dios no ha revelado. Esta es la misma tesis sobre la cual Lutero establece una crítica formal a la religión. [...] La religión 'no revelada' hace que el ser humano se crea protagonista de su propia salvación y sujeto de su propio cambio. La religión comienza por crear en el ser humano, una ambición tímida pero cada vez más activa, de donde surge el orgullo 'espiritualista' y 'piadoso' de quienes se atreven a disputarle a Dios su gloria. Toda religión 'de la gloria' es una negación de la obra de Cristo. ${ }^{3}$

Para Lutero esa obra de Cristo es en cuanto al contenido la revelación de la justicia de Dios. El término de la justicia es la palabra clave del nuevo entendimiento del Evangelio en la Reforma. Durante años Lutero había odiado ese concepto, porque lo había comprendido según la forma de pensar filosófica y jurídica habitual en aquel entonces. Él se imaginaba un Dios que recompensaba y castigaba rigurosamente en conformidad con los méritos y las acciones de las personas; era un Dios que practicaba una justicia formal o activa. Dios mismo es justo y le da a cada ser humano lo que le corresponde. Es una justicia que distribuye y que se basa en las exigencias de la ley. En esa concepción se funda todo el sistema de pensar y actuar de la Edad Media, en las esferas del religioso, del político y del social.

El mundo medieval era profundamente religioso, toda la vida giraba en torno a Dios y la preocupación por la salvación eterna. Las enfermedades, epidemias y guerras amenazaban constantemente la vida y planteaban la cuestión del «más allá» de forma amenazante. Se creía que en el día del juicio, Dios iba a actuar como juez, impartiendo rigurosamente justicia según méritos y servicios, por lo tanto, había que asegurarse desde el principio.

La práctica sacramental de la Iglesia ofrecía un acompañamiento durante todas las fases de la vida y un apoyo espiritual a través de la cadena de los siete sacramentos. Al mismo tiempo, reforzaba los miedos religiosos, ya que podía negarse la gracia por un pecado mortal, lo que también fortalecía la sumisión mental y espiritual al poder y a la primacía absoluta de los sacerdotes. Como también el sistema político y social estaba legitimado religiosamente (desde la institución divina del reinado y todas sus autoridades hasta la estructura estamental del feudalismo) la obediencia y sumisión pasaron a ser virtudes religiosas.

El cambio de una sociedad agraria a una mercantilista provocó inseguridad y nuevos miedos existenciales. El sistema de indulgencias se aprovechaba hábilmente de ese sentimiento general de miedo. Lutero trabajó hasta el agotamiento como monje en ese sistema, con mucha entrega espiritual y disciplina; sin embargo, nunca estuvo seguro de su salvación ni pudo encontrar la paz hasta que se topó, en su lectura de Pablo (Ro 1.17), con una forma totalmente distinta de entender la justicia divina. Él mismo describe ese descubrimiento así:

Entonces Dios tuvo misericordia de mí. Día y noche yo estaba meditando para comprender la conexión de las palabras, es decir: 'La justicia de Dios se revela en él, como está escrito: el justo

3. Cassese, Lutero ..., XVI. 
vive por la fe'. Ahí empecé a entender la justicia de Dios como una justicia por la cual el justo vive como por un don de Dios, a saber, por la fe. Noté que esto tenía el siguiente sentido: por el Evangelio se revela la justicia de Dios, la justicia «pasiva»; mediante la cual Dios misericordioso nos justifica por la fe, como está escrito: 'El justo vive por la fe.' Ahora me sentí totalmente renacido. Las puertas se habían abierto y yo había entrado en el paraíso. De inmediato toda la Escritura tomó otro aspecto para mí. Acto seguido recorrí la Escritura tal como la conservaba en la memoria y encontré también en otras palabras un sentido análogo. Por ejemplo: la obra de Dios es la obra que Dios realiza en nosotros; la virtud de Dios significa la virtud por la cual nos hace poderosos; la sabiduría de Dios es aquella por la cual nos hace sabios. Lo mismo sucede con la fortaleza de Dios, la salud de Dios, la gloria de Dios. Si antes había odiado con gran encono la frase 'justicia de Dios', con tanto más amor la ensalcé ahora porque me resultaba dulcísima. De este modo aquel pasaje de Pablo fue para mí la puerta del paraíso. ${ }^{4}$

El paraíso significó para Lutero la liberación de un sistema completo del miedo y resultó en su crítica de todos los poderes de su tiempo, de la religión oficial, de la Iglesia con el Papado, la práctica de las indulgencias y su jerarquía, del Estado y de la Economía en sus alianzas con la Iglesia. Todos esos siguen a su juicio la misma lógica de una justicia que distribuye.

No obstante, el descubrimiento de Lutero fue que Pablo estaba hablando de la justicia en otro sentido. Pablo se basa en el concepto de justicia del Antiguo Testamento. Allí la justicia se refiere a la fidelidad al pacto (zedaka). Cuando se dice que Dios es justo, es a partir de la experiencia de que Dios permanece fiel a su pacto con el pueblo de Israel a pesar de los continuos rompimientos de ese pacto por parte del pueblo. Dios considera a este pueblo infiel como digno de su pacto, es más, a pesar de no cumplir con sus condiciones siempre vuelve a restablecer el pacto con él.

En este sentido, justicia significa, por un lado, el ser reconocido por Dios y, por otro lado, la fuerza transformadora de Dios. Esa justicia no depende de las leyes ni de su cumplimiento, sino que tiene que ver con misericordia, perdón y con la voluntad de nueva creación. El nuevo concepto de justicia es pasivo, es una justicia recibida y regalada en el sentido de ser reconocido a partir de la promesa de Dios, el Evangelio. ¿Pero cómo se concreta la apropiación de esa justicia pasiva?

Para Lutero es claro que Dios quiere realizar su justicia en el mundo y en el ser humano. Por eso también les da su justicia a los impíos, o sea les ofrece su pacto. En su justicia, Dios actúa transformando el mundo. Así es como se presenta su justicia, Él mismo como fuerza creadora y redentora. La dimensión forense de la justificación, o sea la declaración de justicia, se complementa para Lutero con la dimensión efectiva, la regeneración o santificación. Por lo tanto, vivir en la justicia de Dios libera para una nueva vida en el Espíritu de Cristo, liberada de las obligaciones de la ley, de la moral convencional y de la lógica del mérito. Eso abre una grandiosa libertad del actuar.

Sin embargo, no se trata de una libertad absoluta. El hecho de que la fe se demuestre en el comportamiento correspondiente se basa en el ser mismo de la fe. La verdadera fe no puede existir sin obras. En la fe se experimenta el amor de Dios como fuerza

4. Martín Lutero, «Prefacio al primer tomo de los escritos latinos» (1545), en Obras ... I, 337s. 
transformadora y renovadora, y esta se muestra luego en las obras y el comportamiento. La famosa imagen de Lutero del árbol y los frutos lo explica claramente:

Las obras buenas y justas jamás hacen al hombre bueno y justo, sino que el hombre bueno y justo realiza obras buenas y justas. [...] Se desprende de esto que la persona habrá de ser ya buena y justa antes de realizar buenas obras, o sea, que dichas obras emanan de la persona justa y buena, como dice Cristo [Mt 7.18]: 'EI árbol malo no lleva buenos frutos; el árbol bueno no da frutos maIos'. Ahora bien, está claro que ni los frutos llevan aI árbol ni se producen los árboles en los frutos, sino que por el contrario los árboles llevan los frutos y los frutos crecen en los árboles. ${ }^{5}$

Con sus obras, la persona incluso se transforma en colaboradora de Dios, como explica Lutero en su escrito La voluntad determinada. El Espíritu de Dios actúa sin la colaboración del ser humano, pero Él no quiere actuar solamente en nosotros, sino también con nosotros ${ }^{6}$. Por lo tanto, no hay una colaboración para la salvación, que continúa siendo solo por gracia, pero sí una colaboración en el ámbito de la iustitia civilis, la justicia en el mundo.

De esa manera el nuevo - o mejor el re-descubierto - entendimiento de la justicia de Dios nos guía a la fe como responsabilidad por el mundo.

\section{La ética discursiva de los mandamientos}

Como consecuencia, el nuevo concepto de la justicia causó un cambio revolucionario de la ética tradicional. Se revela en la directriz de las reflexiones éticas de Lutero: «No nos volvemos justos al hacer lo justo, sino al contrario: como somos justos hacemos lo justo» ${ }^{7}$.

Esta frase documenta la ruptura con la ética cristiana medieval la cual era una doctrina de la virtud. Se basaba en las cuatro virtudes centrales que había descrito Aristóteles: inteligencia, valentía, moderación y justicia, que se adquieren mediante la práctica permanente. De esta manera, el alma adquiere solidez y resistencia, y forma así el carácter de una persona, su hábito. Como consecuencia, la vida ética se construye por medio

5. Martín Lutero, La libertad cristiana (1520), en Obras ... I, 161.

6. «Antes de ser renovado y transformado en nueva creatura deI reino deI Espíritu, el hombre no hace nada ni realiza esfuerzo alguno que lo acondicione para esta renovación y este reino; y luego, una vez regenerado, tampoco hace nada ni realiza esfuerzo alguno que le asegure la permanencia en este reino, sino que ambas cosas se deben exclusivamente aI Espíritu que obra en nosotros: él nos regenera sin intervención nuestra, y nos conserva una vez regenerados [...] Sin embargo, Dios no obra sin que nosotros participemos, dado que para esto mismo nos hizo renacer y nos conserva: para que él obre en nosotros y nosotros cooperemos con él». La voluntad determinada (1525), en Obras ... IV, 274.

7. Martín Lutero, Comentario de la carta a los Romanos (1515/16), sobre Ro 3.20, WA 56, 255; [en la edición científica de las obras completas de Lutero, en alemán, conocida por la sigla WA, para Weimarer Ausgabe, Edición de Weimar (D. Martin Luthers Werke: Kritische Gesamtausgabe, ed. por Hermann Böhlau y Nachfolger), publicada en Weimar desde 1883 hasta el 1999, en un total de 104 tomos con 117 volúmenes]. trad. por Dámaris Zijlstra Arduin, en Martín Hoffmann, La locura de la cruz: La teología de Martín Lutero. Textos originales e interpretaciones (San José: DEI, 2014), 170. 
de acciones metódicas y educativas; luego llega la habituación y la virtud se convierte en algo muy propio. La ética cristiana había agregado a estas cuatro virtudes centrales las virtudes cristianas de fe, esperanza y amor. El fin del camino ético es alcanzar la justicia que vale ante Dios.

Lutero niega este sistema lógico y pedagógico y lo pone por así decirlo de cabeza en sus escritos fundamentales La libertad cristiana y Las buenas obras. Para él, en ese sistema únicamente se encuentran las obras de la ley. El punto de partida de esta afirmación es, por un lado, su experiencia personal de fallar en ese camino hacia Dios, y por otro lado, y unido a esto, el descubrimiento bíblico liberador de la justicia obsequiada por Dios. Ella es la raíz de la libertad cristiana, una libertad incluso frente a la propia conducta y a las propias obras. El ser humano justificado es libre frente a sus obras. La persona solo es esclava en tanto las obras, sean buenas o malas, definan su ser; en ese caso es prisionero de sus propias obras y permanece encadenado a ellas como un esclavo. Lutero dice: «Cuando miras solamente lo que haces, ya no puedes llamarte cristiano. Es realmente cierto que se deben realizar buenas obras, ayudar a los demás, aconsejar y dar, pero no por eso uno se puede llamar cristiano y no por eso uno es un cristiano». ${ }^{8}$

Aquí se muestra claramente por qué se produjo la Reforma. Porque aquí no se corrigen algunos daños o carencias, sino que se rechaza el ideal que determinaba toda la existencia durante la Edad Media, el ideal de que la persona debía ejercitar sus virtudes para alcanzar la justicia.

Entonces, ¿qué significado tienen en esa concepción las buenas obras, la conducta ética? Para Lutero las obras son aquello que sigue automáticamente a la fe, así como un buen árbol automáticamente da buenos frutos. Por lo tanto, las obras son únicamente una señal de que la fe está ahí, pero ya no deciden sobre el valor de la persona frente a Dios. Ya no son decisivas para su identidad. Sin embargo, sería incorrecto decir que en la ética de Lutero las obras ya no tienen importancia. Claro que la tienen, pero ya no es una importancia final, con una determinada meta o finalidad, esto es, ser reconocido por Dios, sino con una importancia consecutiva. Para Lutero el punto de la referencia de las obras buenas no es la persona misma, sino la necesidad del prójimo. Así explica en su famoso escrito La libertad cristiana en su tesis 30:

Se deduce de todo lo dicho que el cristiano no vive en sí mismo, sino en Cristo y el prójimo; en Cristo por la fe, en el prójimo por el amor. Por la fe sale el cristiano de sí mismo y va a Dios; de Dios desciende el cristiano al prójimo por el amor. Pero siempre permanece en Dios y en el amor divino ... He aqui la libertad verdadera, espiritual y cristiana que libra al corazón de todo pecado, mandamiento y ley; la libertad que supera a toda otra como los cielos superan la tierra. ${ }^{9}$

8. Martín Lutero, Apostilla de verano (1526): Evang. am 24. So. n. Trin., Mt 9.18-26 (WA 10 I/II, 431), en Hoffmann, La locura ..., 170

9. Lutero, La libertad ..., 167. 
Aquí Lutero presenta una forma de ética la cual se puede describir como «ética del margen», es decir una ética al practicar la libertad, impulsada por el amor del prójimo y orientado a la necesidad del prójimo. Esos motivos son consecuencias de la cruz que expresa el amor de Dios, la solidaridad de Dios con los sufrientes y la voluntad de Dios de superar el mal y conservar la libertad. Para concretizar ese amor Lutero a menudo recurrió a los diez mandamientos, pero no en sentido de normas absolutas, sino de directrices. Por lo tanto, podemos caracterizar la ética de Lutero también como una ética discursiva de los mandamientos. ¿Qué significa eso concretamente?

Lutero se basa en el amor, la «ley de Cristo» (Gl. 6.2) porque el creyente es tocado y transformado por ese amor de Cristo en el Evangelio; Lutero incluso dice que el creyente es igualado a la Palabra. Orientarse hacia el prójimo y su necesidad, transforma ese amor en una metanorma, por decirlo de alguna manera, que ayuda creativamente a encontrar la regla adecuada para la situación concreta. Así abre un discurso con la situación real, las normas preestablecidas de la tradición y las perspectivas vitales del Evangelio. De esta forma el mandamiento del amor puede ser comprendido también como regla de conducta flexible para alcanzar un ethos contextual de acuerdo con el Evangelio. En la disputa contra los Antinomianos, Lutero incluso llega a decir que en la fe en Cristo el cristiano puede crear nuevos decálogos que son más claros que los de Moisés:

53. Incluso podemos establecer nuevos decálogos como lo hace Pablo en todas sus cartas y también como lo hace Pedro y especialmente como lo hace Cristo en el Evangelio.

54. Y esos decálogos son más excelentes que el decálogo de Moisés, así como el rostro de Cristo ilumina con más fulgor que el semblante de Moisés.

55. Si incluso los gentiles, a pesar de su naturaleza corrupta, pueden imaginarse algo de Dios y volverse ley, como dice Ro 2.56, con más razón puede Pablo o un cristiano íntegro, lleno del Espíritu, establecer un decálogo y juzgar sobre todas las cosas correctamente. ${ }^{10}$

Por lo tanto, si existe un conflicto entre Cristo y la ley, siempre debe prevalecer Cristo. Así abre Lutero la ética a la situación concreta. Es recién en el discurso concreto que se cristalizan las normas de conducta, siempre teniendo en cuenta la perspectiva del amor.

Para ello Lutero recurre nuevamente a los mandamientos de Dios y a la ley natural. A primera vista, pareciera una contradicción o una tensión sin resolver. Al reducir la importancia de la ley y de los principios fijos, por un lado, y al orientarse a la humanidad indicada por estos, por otro lado, Lutero marca el margen en el que deben tomarse las decisiones éticas.

Lutero lleva esto a cabo paradigmáticamente en su Interpretación de los diez mandamientos del Catecismo Menor. Para comenzar pone todos los mandamientos bajo el lema del primer mandamiento «tenemos que temer, amar y confiar en Dios por sobre todas las cosas». Y así relaciona los otros nueve mandamientos con la manifestación del Dios único. Aunque Lutero deja de lado en el Catecismo la ampliación del Antiguo Testamento

10. Martín Lutero, Tesis para cinco disputas sobre Romanos 3. 28 - Sobre la fe (1535-1537; WA 39/I, 47), en Hoffmann, La locura ..., $158 \mathrm{~s}$. 
«yo soy el Señor tu Dios» o «yo te saqué de Egipto, del país donde eras esclavo» (Ex 20.2), esta referencia a la historia de la liberación de Israel sigue formando parte del trasfondo de su interpretación de los mandamientos. Esta acción liberadora de Dios es previa a los mandamientos y les da su sentido. Se trata de conservar la libertad obtenida, de que la misericordia de Dios se vuelva base de la convivencia humana y de que la vida en sociedad refleje el carácter de esa experiencia liberadora. La interpretación de cada mandamiento comienza, por lo tanto, siempre con la frase «tenemos que temer y amar a Dios». Esto vincula el mandamiento, la regla de vida, con el Dador de vida.

Llama la atención que Lutero luego no formule los mandamientos únicamente de forma negativa, o sea solo como prohibiciones. Estos representan las vallas protectoras detrás de las cuales la libertad y la dignidad humana son heridas y destruidas. Así fueron comprendidos los diez mandamientos casi siempre en la tradición cristiana y por eso la educación ética y la proclamación muchas veces tenían un tono restrictivo y amenazador: «no debes, no está permitido». Sin embargo, Lutero hace siempre el giro hacia una interpretación positiva. Esta interpretación nos revela el verdadero sentido de los mandamientos bajo la premisa del amor: se trata siempre de fomentar la vida y ayudar al prójimo a vivir su vida en dignidad humana. Esto podemos ejemplificarlo con la interpretación del quinto mandamiento: «No matarás. ¿Qué quiere decir esto? Respuesta: Debemos temer y amar a Dios de modo que no hagamos daño o mal materiales algunos a nuestro prójimo en su cuerpo y vida, sino que le ayudemos y hagamos prosperar en todas las necesidades de su vida». ${ }^{11}$

Luego de concretar la prohibición de matar («...que no hagamos daño o mal materiales algunos a nuestro prójimo en su cuerpo y vida»), él menciona la intención verdadera y vivificadora del mandamiento: «... sino que le ayudemos y hagamos prosperar en todas las necesidades de su vida». Una vida desde la justicia de Dios, en comunidad con Él, significa; por lo tanto, no solo renunciar a matar, sino que también se concreta en el fomento de la vida del prójimo, especialmente en situaciones de necesidad o indigencia. Aparentemente, Lutero no puede ni quiere describirlo más concretamente porque no pretende desarrollar una casuística, sino abrir espacios al amor, y buscar aquello que transforma la necesidad, tal como lo señalan los mandamientos.

Así, Lutero recupera los mandamientos como directrices o reglas de conducta para una vida más humana bajo la premisa del amor al prójimo luego de haber limitado la ley a su uso civil y teológico. El punto de partida de Lutero en la Palabra de la cruz y en la justificación solo por la fe lo lleva a desarrollar una ética con cierta perspectiva que trabaja con distinciones y así desarrolla una dinámica que es capaz de valorar los respectivos contextos en la luz de los gobiernos espiritual y temporal de Dios. Eso permite a Lutero también meterse en lo político cuando dio consejos directos a los príncipes de su tiempo para su actuar político ${ }^{12}$ o en lo económico cuando criticó fuertemente, por ejemplo, las practicas del comercio y la usura. ${ }^{13}$

11. Martín Lutero, Catecismo Menor (1529): Los diez mandamientos, en Obras ... V, 18s.

12. Ver La autoridad secular (1523), en Obras ... II, 155-160; y El Magnificat (1521), en Obras ... VI, 415-417.

13. Ver Sermón sobre la usura (1519; WA 6,3-8), en Hoffmann. La locura ..., 216-218 y Comercio y usura (1524), en Obras ... II, 103-120. 
La Reforma es ante todo un proceso y no solo un evento, un método no solo una gesta; un movimiento de renovación dentro de la iglesia y no una nueva iglesia. La Reforma sigue estando vigente porque como proceso sigue fermentando cambios y transformaciones, porque como método sigue proveyendo pautas para repensar. Reinterpretar el quehacer teológico y como movimiento la Reforma sigue interesada en renovar y reorientar a la iglesia hacia una forma de existir relevante y afirmativa para el ser humano. ${ }^{14}$

\section{Conclusión - La actualidad de la Reforma}

Como se ha visto, la Reforma es más que una época histórica o la eliminación de unos abusos de las prácticas de la Iglesia. Su caracterización por Cassese da en el clavo:

Proceso, método y movimiento como características mantienen la teología y la iglesia en un modo fluido. Una tradición fija, un sistema cerrado de dogmas o una iglesia institucional van a perder el espíritu de Jesús. «Ser un proceso» significa que la Reforma siempre es una Reforma inconclusa, porque el estado de la teología y de la iglesia nunca corresponden completamente con el esperado Reino de Dios. «Ser un método» significa que la Reforma recibe su dinámica por el recurso a la fuente de la Biblia y por el descubrimiento de sus perspectivas de una vida plena detrás de las puras letras. «Movimiento» entonces significa que la iglesia en el fondo debería ser una comunidad en camino, enfrentándose con los desafíos contemporáneos y renovándose siempre de nuevo para cumplir con el seguimiento. El fermento de esa dinámica es «el mensaje de la cruz» - como dice Cassese ${ }^{15}$-, la justicia de Dios como visión de una vida humana y el amor al prójimo como regla flexible de la ética.

Una teología e iglesia que se basan en este paradigma crean un pensar y actuar crítico en contra de otros paradigmas dominantes de la civilización moderna. A menudo se habla sobre la así llamada postmodernidad para legitimar la pluralidad de las cosmovisiones, convicciones y morales en contra de la dominación de un «gran cuento», sea el cristianismo o el socialismo o otras ideologías. De hecho, la postmodernidad es marcada por la prioridad de una esfera de la vida, de la economía. Mientras la modernidad representó las grandes ideas de la razón, del progreso y de la libertad, la postmodernidad ha cambiado completamente esos valores por la liberalización y globalización del sistema económico que sigue su propia lógica.

La razón se ha convertido en eficiencia como prototipo de la racionalidad económica, el progreso se ha convertido en crecimiento de la economía y la libertad civil se ha convertido en libertad del mercado. Pero las varias crisis de la civilización basada en esas ideas son evidentes hoy en día.

Estamos confrontados con las crisis de la ecología, de la migración, de la progresiva división social entre pobres y ricos, de la alimentación, de la energía, de las finanzas y con una alta tasa de violencia y guerras. Evidentemente tienen causas comunes en la manera de vivir y de producir bajo las condiciones del capitalismo. Por lo tanto, se plantean

14. Cassese, Lutero ..., XIIIs.

15. Ibid., XIV. 
preguntas por los objetivos de esa manera económica. ¿Sirve todavía para la vida común o solo para el beneficio de unos pocos? ¿Cómo se puede regular la convivencia de los seres humanos de una manera justa? Esas fundamentales preguntas éticas provocan una abierta disputa civil. ${ }^{16} \mathrm{La}$ actualidad de la Reforma se demuestra en su nuevo paradigma de pensar y de actuar, o sea en su potencial crítico a partir del Crucificado y de sus perspectivas constructivas para la humanidad y la convivencia a partir de la justicia de Dios. Esa Reforma nunca está acabada.

\section{ABSTRACT}

\section{The Reform - a New Paradigm of the Theology}

500 years after the origin of Protestantism in the Reformation we have to ask: What is the significance of the Reformation today? The author claims that the importance of the Reformation goes beyond a historical epoch or a theological debate in its time. Rather, the Reformation is a permanent process, a movement, and a certain method of theological work. Referring to the theology of the cross of the apostle Paul, Martin Luther, the initiator of the Reformation, developed a new paradigm of theology. It is characterized by three aspects: The cross as epistemological principle, the justice of God as essential content of the gospel, and a discursive ethic of the commandments. This paradigm of theology facilitates a continuous renovation and transformation of churches and theology in the face of contemporary challenges like the crises of ecology, economy, social justice, and violence and wars. The relevance of the Reformation has to be seen in its new way of thinking and acting, that means in its critical potential based in the Crucified and its constructive perspectives for humanity and coexistence from the perspective of the justice of God.

Key words: Reformation, paradigm, theology of the cross, liberating justice, discursive ethic, coexistence, humanity.

\section{RÉSUMÉ}

\section{La Reforme - un nouveau paradigme de la théologie}

500 ans après l'origine du protestantisme dans la Reforme, la question suivante est posée : Qu'estce que signifie la Reforme aujourd'hui ? L'auteur soutient que l'importance va au-delà d'une époque historique ou d'une controverse théologique dans son temps. La Reforme est plutôt un processus permanent, un mouvement et une certaine méthode du travail théologique. En partant de la théologie de l'apôtre Paul, le réformateur Martin Luther a développé un nouveau paradigme de la théologie, lequel est caractérisé par trois aspects : la croix comme principe épistémologique, la justice de Dieu comme contenu essentiel de l'Évangile, et une éthique discursive des commandements. Ce paradigme de la théologie rend possible un renouvellement et une transformation en continue des églises et de la théologie face aux défis actuels comme la crise de l'écologie, de l'économie, de la justice sociale, de la violence et des guerres. La mise au jour de la Réforme se met en évidence dans sa nouvelle manière de penser et d'agir, c'est-à-dire, dans son potentiel critique à partir du Crucifié et ses perspectives constructives pour l'humanité et la coexistence dès la justice de Dieu.

Mots-clés : Reforme, paradigme, théologie de la croix, justice libératrice, étique discursive, coexistence, humanité.

16. Vea p.e. la contribución del grupo internacional «Radicalizando la Reforma». El ha editado 94 tesis para la conmemoración de la Reforma 2017 bajo el título Radicalizando la Reforma provocados por la Biblia y las crisis actuales (www.reformation-radical.com) y también: Radicalizando la Reforma: Otra teología para otro mundo, ed. Martín Hoffmann, Daniel Beros y Ruth Mooney (San José: Editorial SEBILA, 2016). 


\section{Bibliografía}

Cassese, Giacomo, y Eliseo Pérez-Álvarez eds. Lutero al Habla. Buenos Aires: Ediciones La Aurora, 2005.

Hoffmann, Martín. La locura de la cruz. La teología de Martín Lutero. Textos originales e interpretaciones. San José: DEI, 2014.

Hoffmann, Martín. Daniel Beros y Ruth Mooney, ed. Radicalizando la Reforma: Otra teología para otro mundo. San José: Editorial SEBILA, 2016.

Hoffmann, Martín. ed. Radicalizando la Reforma. Provocados por la Biblia y las crisis actuales. Las 94 tesis. Aportes Teológicos №. 1 (2015): 9-48.

Lutero, Martín. Comentario de la carta a los Romanos (1515/16). En D. Martin Luthers Werke: Kritische Gesamtausgabe, ed. por Hermann Böhlau y Nachfolger, Weimar 1883 ss. (=Weimarer Ausgabe /Edición de Weimar =WA) tomo 56, Obras de Martín Lutero X; partes trad. por Dámaris Zijlstra Arduin en Hoffmann, Martín. La locura de la cruz, 85s.,108, 110s.

. Sermón sobre la usura (1519), WA 6,3-8 y en Español en Hoffmann. La locura de la cruz, 216-218.

Lutero, Martín. Obras des Martín Lutero. Buenos Aires, Argentina: Editorial Paidós/El Escudo y Ediciones La Aurora, $1967 \mathrm{ss}$.

. La disputación de Heidelberg (1518). En Obras de Martín Lutero I, 29-46.

La libertad cristiana (1520). En Obras de Martín Lutero I, 149-167.

El Magnificat (1521). En Obras de Martín Lutero VI, 377-436.

La autoridad secular (1523). En Obras de Martín Lutero II, 129-162.

Comercio y usura (1524). En Obras de Martín Lutero II, 103-121.

La voluntad determinada (1525). Obras de Martín Lutero IV.

Apostilla de verano (1526). Evang. am 24. So. n. Trin., Mt 9.18-26 (WA 10 I/II, 431). En Hoffmann.

La locura de la cruz, 170.

Catecismo Menor (1529). En Obras de Martín Lutero V, 13-34.

Tesis para cinco disputas sobre Romanos 3.28 - Sobre la fe (1535-1537). WA 39/I, 47. En Hoffmann.

La locura de la cruz, 90-91.

Prefacio al primer tomo de los escritos latinos (1545). En Obras de Martín Lutero I, 331-338. 